\title{
Achieving negative margin in Bismuth III and IV hilar cholangiocarcinoma without major hepatectomy
} Ghimire R ${ }^{1}$ 四, Amatya KS², Thapa PB ${ }^{3}$

${ }^{1}$ Roshan Ghimire, Assistant Professor, Department of Surgery, Kathmandu Medical College Teaching Hospital, Kathmandu, Nepal; ${ }^{2}$ Kapendra Shekhar Amatya, Department of Surgical Oncology, Nepal Cancer Hospital, Nepal; ${ }^{3}$ Prabin Bikram Thapa, Professor, Department of Surgery, Kathmandu Medical College Teaching Hospital, Kathmandu, Nepal.

\begin{abstract}
Background: Several studies have proposed en bloc resection with major hepatectomy to achieve negative margin in hilar cholangiocarcinoma. These major hepatectomy have morbidity in some subgroups of patients with limited functional hepatic reserve.

Methodology: Patients with Bismuth type III and IV hilar cholangiocarcinoma with underlying early cirrhosis that underwent liver parenchymal preserving bilobar wedge liver resection between July 2017 and June 2020 were included in the study.

Results: Twelve patients underwent liver parenchymal preserving bilobar wedge liver resection between July 2017 and June 2020. Mean age of the study population was $70.83 \pm 3.58$ years. Reconstruction of biliary tree was done with intrahepatic cholangiojejunostomy in Roux en $Y$ fashion in multiple segmental hepatic stomas.

Conclusion: Liver parenchymal preserving surgery should be considered in hilar cholangiocarcinoma in selected cases to prevent suspicion increasing morbidity and mortality due to post-operative liver failure.
\end{abstract}

Key words: Hilar cholangiocarcinoma; Liver resection; Negative margin.

\section{INTRODUCTION}

holangiocarcinoma (CCA) is an aggressive
malignancy that arises from the epithelial cells of
the biliary tree among which $50-60 \%$ of tumors are hilar
CCA (Klatskin' tumour), $10 \%$ are intrahepatic and $20-30 \%$
are extrahepatic distal bile duct tumours. ${ }^{1}$

Access this article online

Website: www.jkmc.com.np

DOI: https://doi.org/10.3126/jkmc.v9i3.36585

\section{HOW TO CITE}

Ghimire R, Amatya KS, Thapa PB. Achieving negative margin in Bismuth III and IV hilar cholangiocarcinoma without major hepatectomy. J Kathmandu Med Coll. 2020;9(3):161-4.

Address for correspondence

\section{Dr. Roshan Ghimire}

Assistant Professor, Department of Surgery

Kathmandu Medical College Teaching Hospital

Kathmandu, Nepal

E-mail: roshanghimire194@gmail.com

Copyright ๔ 2020 Journal of Kathmandu Medical College (JKMC)

ISSN: 2019-1785 (Print), 2091-1793 (Online)

(i) (S) This work is licensed under a Creative Commons Attribution-Non Commercial 4.0 International License.
Depending upon the stage of disease, a wide array of treatment options are available ranging from local excision to liver transplantation. Surgical resection is the mainstay of curative treatment for CCA. However, majority of the cases (70-80\%) are unresectable as it is limited by tumor characteristics such as multifocality, bilobar lesions, large central lesions andvascular encasement. ${ }^{1,2,3}$

Several studies have proposed en bloc resection of extrahepatic bile duct with major hepatectomy for achievement of histologically cancer free resection margin. ${ }^{4,5}$ Attempts of major resection in patients with high bilirubin and underlying early cirrhosis (Child $A$ and $B$ ) are associated with high perioperative morbidity because of the limited functional reserve. ${ }^{6}$

Inthisstudy, weassessedROresectionandmorbidityamong bismuth type III and IV hilarcholangiocarcinoma who underwent liver parenchymal preserving bilobar wedge liver resection in a single institution.

\section{METHODOLOGY}

This study was conducted at Kathmandu Medical College Teaching Hospital and Nepal Cancer Hospital, Nepal. 
We analyzed prospectively collected hospital records of patients with hilar cholangiocarcinoma who had undergone liver parenchymal preserving bilobar wedge liver resection between July 2017 and June 2020 with underlying early cirrhosis. Proximal tumor infiltration into the biliary tract was categorized according to the Bismuth-Corlette classification.? Patients who had undergone major hepatectomy and those which were abandoned per-operatively were excluded in the series. Repeated frozen section positive of proximal margin were excluded in the study population. Based on per-operative ultrasound findings and assessment of surgeons, the disease free biliary ducts were identified and then anastomosis was done.

The parameters assessed included age at surgery, sex, bilirubin level, status of liver, tumor characteristics, postoperative complications and recurrence-free survival after surgery. The diagnosis of liver cirrhosis was made on the basis of imaging and per-operative findings. The diagnosis of malignancy was established by histopathological findings. Results were expressed as mean \pm standard deviation and categorical variables in percentage. Statistical analyses were performed with SPSS software version 20 .

\section{RESULTS}

Twelve patients with cholangiocarcinoma involving hepatic duct bifurcation underwent liver parenchymal preserving bilobar resection at Kathmandu medical College and Teaching Hospital, Nepal between July 2017 and June 2020. Amongst these 12 patients, 7 were men and 5 were women. The patients' ages ranged from 65 years to 78 years, with a mean age of $70.83 \pm 3.58$ years. None of the patients had received neo-adjuvant therapy. Preoperative characteristics are described in table 1.

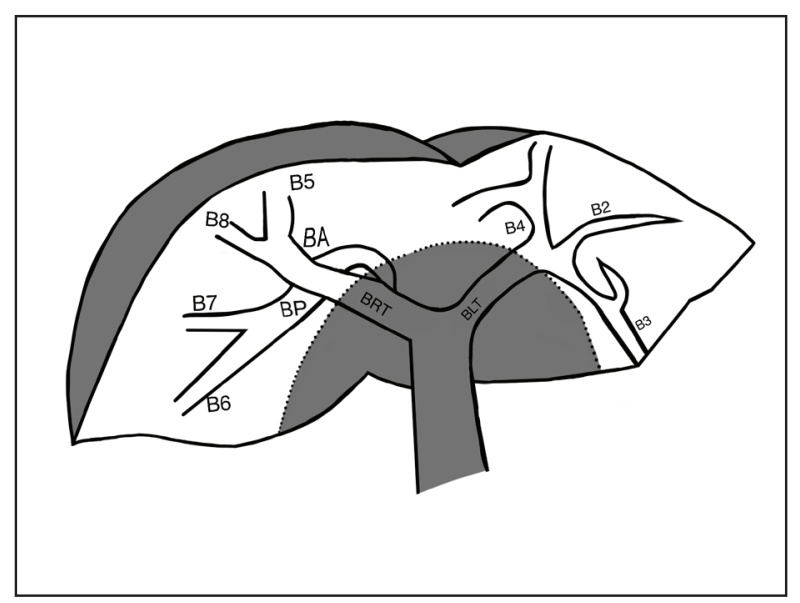

Figure 1: Schematic of bilobar wedge resection
Table 1: Preoperative characteristics

\begin{tabular}{|c|c|}
\hline Patient characteristics & Number \\
\hline Bismuth classification & \\
\hline Illa & 5 \\
\hline IIlb & 3 \\
IV & 4 \\
\hline Bilirubin level (mg/dl) & \\
\hline$<5$ & 6 \\
\hline $5-10$ & 4 \\
\hline $10-15$ & 1 \\
\hline$>15$ & 1 \\
\hline Preoperative Biliary drainage & \\
\hline ERCP alone & 0 \\
\hline PTBD alone & 5 \\
\hline Both & 4 \\
\hline None & 3 \\
\hline
\end{tabular}

Intraoperative ultrasound was done to assess the tumor and margin. The bile duct margin assessment was done by frozen biopsy. All patients achieved R0 resection based on frozen biopsy. Reconstruction of biliary tree was done with intrahepatic cholangiojejunostomy in Roux en $Y$ fashion in multiple segmental hepatic stomas. Cholangiojejunostomy was done in a singlelayer interrupted sutures with 7-0 Polydioxanine suture and the number of anastomosis is shown in table 2.

In one case of type IV Hilar CCA, caudate duct was reconstructed as caudate lobe was hypertrophied. All patients had negative distal margin. Regarding proximal margin, out of the twelve patients, 7 patients achieved more than $5 \mathrm{~mm}$ resection margin and in 5 patients resection margin was less than $5 \mathrm{~mm}$. The postoperative morbidity has been charted in table 3 .

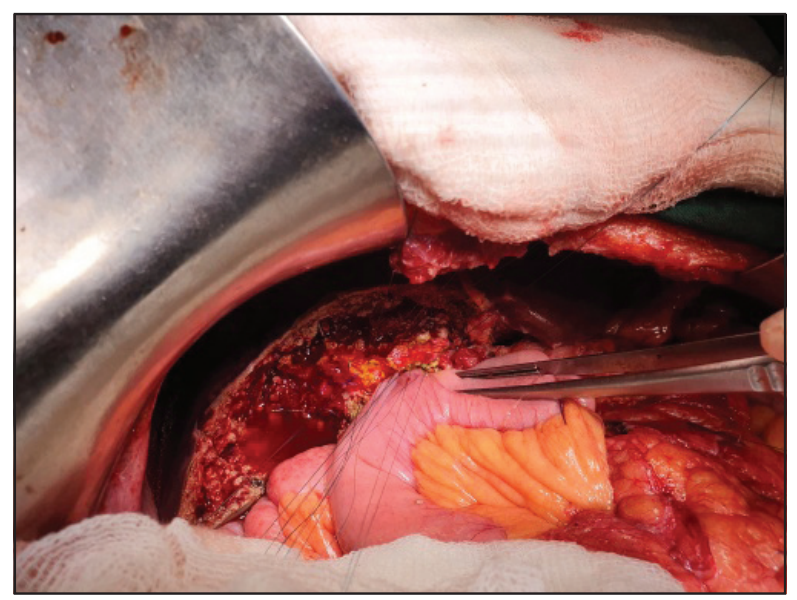

Figure 2: intraoperative findings after the surgery 
Table 2: Number of biliary anastomosis in different types of hilar CCA

\begin{tabular}{|c|c|c|c|}
\hline $\begin{array}{l}\text { Number of biliary } \\
\text { anastomosis }\end{array}$ & $\begin{array}{l}\text { Number of } \\
\text { cases }\end{array}$ & $\begin{array}{l}\text { Type of hilar } \\
\text { cholangiocarcinoma }\end{array}$ & Remarks \\
\hline 2 & 3 & $\begin{array}{l}\text { Type III a (2) } \\
\text { Type III b (1) }\end{array}$ & $\begin{array}{l}\text { Right anterior and posterior ducts in common sheath and } \\
\text { Segment } 2 \text { and } 3 \text { in common Sheath }\end{array}$ \\
\hline 3 & 5 & $\begin{array}{l}\text { Type III a (3) } \\
\text { Type IV (2) }\end{array}$ & $\begin{array}{l}\text { Right anterior duct, right posterior duct and Segment } 2 \text { and } \\
3 \text { in common Sheath }\end{array}$ \\
\hline 4 & 3 & $\begin{array}{l}\text { Type III b (1) } \\
\text { Type IV (2) }\end{array}$ & $\begin{array}{l}\text { One case- Right anterior duct, right posterior duct, Segment } 2 \\
\text { and } 3 \text { in common Sheath and segment } 4 \text {. } \\
\text { Two cases- Right anterior duct, right posterior duct, Segment } \\
2 \text { and Segment } 3 \text {. }\end{array}$ \\
\hline 5 & 1 & Type IV (1) & $\begin{array}{l}\text { Right anterior duct, right posterior duct, Segment } 2 \text { and } 3 \text { in } \\
\text { common Sheath, segment } 4 \text { and caudate duct. }\end{array}$ \\
\hline
\end{tabular}

Table 3: Postoperative details

\begin{tabular}{|l|l|}
\hline Patient Characteristics & Number \\
\hline $\begin{array}{l}\text { Morbidity (Clavien Dindo classification) } \\
\text { Grade } 1 \text { and } 2\end{array}$ & 5 \\
\hline Grade 3 and 4 & 4 \\
\hline Grade 5 (mortality) & 0 \\
\hline Post-operative complications & \\
\hline Wound infection & 5 \\
\hline Cholangitis & 2 \\
\hline Respiratory complication & 2 \\
\hline Biliary cutaneous fistula & 4 \\
\hline Others & 1 \\
\hline
\end{tabular}

Four patients developed biliary cutaneous fistula, out of which two required percutaneous drain placement in the collection. Two patients developed cholangitis which were managed in intensive care unit with intravenous antibiotics.

\section{DISCUSSION}

This study was done to assess negative margin (R0 status) following liver parenchymal preserving bilobar wedge resection procedure for CCA in a single centre in Nepal. Overall, post-operative morbidity was seen in 9 patients (75\%) with major complications (Clavien-Dindo grade 3 and 4 ) occurring in 4 patients (33.3\%).Reconstruction of Biliary tree was done with Roux en $Y$ intrahepatic cholangiojejunostomy in multiple segmental hepatic stomas.

A critical assessment of the patient's preoperative imaging is necessary to determine resectability. ${ }^{7,8}$ The anatomy of the biliary ducts at the hepatic duct confluence ultimately determines whether tumor-free ductal margins can be obtained with preservation of sufficient remnant liver in Bismuth type IV tumors. ${ }^{8,9}$
Our study reports twelve patients with hilar cholangiocarcinoma in elderly with early cirrhosis (Child A and B) with compromised hepatic function. All patients achieved negative margin (R0 status). In this study, the decision to perform liver parenchymal preserving bilobar wedge resection in a patient with hilar cholangiocarcinoma based on the survival probability in the elderly, presence of early cirrhosis(Child A and B) and compromised hepatic function.

Hilar cholangiocarcinoma or Klatskin tumors area group of bile duct carcinoma arising near or at the confluence of the right and left hepatic ducts.9,10,11 Hilar CCA has been grossly classified in polypoid or papillary, nodular, scirrhous constricting or nodular-infiltrating, and diffusely infiltrating types. These types shows different prognosis. Protruding tumors toward the biliary lumen are the polypoid or papillary type whereas a firm tumor bulging from the mucosa is nodular type. Scirrhous or nodularinfiltrating type exhibits only a slight protuberance of the mucosa and involves the thickness of the wall. In diffusely infiltrating type, the tumor has linear extension than the scirrhous constricting type. ${ }^{11,12,13}$ The papillary type is more often resectable and less invasive with the best prognosis. Hilar Cholangiocarcinoma can also be classified macroscopically as papillary and non-papillary (i.e., nodular-sclerosing) types. ${ }^{8}$ Nine of our patients were of the polypoidal variety which could have aided in the negative resection margin. All patients achieved $\mathrm{R} 0$ in frozen section whereas 2 patients turned out as margin positive in final histopathology report.

Though accomplishment of $\mathrm{R} 0$ resection is mandatory in hilar cholangiocarcinoma, it is difficult because of theclose relationship between the biliary confluence and major vessels (Hepatic Artery and Portal Vein). ${ }^{13,14}$ In Hilar CCA, Bismuth type IIIB requires an extended left hepatectomy and the invasion of the RHA usually renders the patient inoperable and the reconstructiondifficult. ${ }^{14,15} \mathrm{n}$ our series, right hepatic artery is replaced and originated from 
SMA in two cases and early division of RHA is noticed in 3 cases. In remaining 4 cases, accessory left hepatic artery was noted. May be because of these findings, separation of RHA and LHA was possible in our series.

Even after extensive studies, the extent of liver resection in hilar cholangiocarcinoma remains controversial. Major liver resection with its higher operative morbidity, should be reserved for selected cases mainly with vascular invasion. ${ }^{15,16}$ Some patients having hilar cholangiocarcinoma with noninvasive and limited spreading lesions can be treated with parenchymal preservation without major hepatectomy. ${ }^{45,15,16}$ Bilobar wedge resection seems to be safe and feasible for selected group of patients of cholangiocarcinoma though we have not discussed about overall survival and recurrence after the surgery.

\section{REFERENCES}

1. Khan SA, Davidson BR, Goldin R, Pereira SP, Rosenberg WM, Taylor-Robinson SD, et al. Guidelines for the diagnosis and treatment of cholangiocarcinoma: consensus document. Gut 2002; 51(Suppl 6): 1-9. [DOI]

2. Lindner $P$, Norrby J, Olausson M, Friman S. Survival after liver transplantation for cholangiocarcinoma has increased during the last decade. Transpl Proc. 2003;35(2):811-2.[DOI]

3. Jarnagin WR. Cholangiocarcinoma of the extrahepatic bile ducts. Semin Surg Oncol. 2000; 19(2):156-76. [DOI]

4. Hirano S, Kondo S, Tanaka E, et al. Outcome of surgical treatment of Hilar cholangiocarcinoma: a special reference to postoperative morbidity and mortality. J Hepatobiliary Pancreat Surg. 2009;17(4):455-62. [DOI]

5. Nagino M, ebata K, Sano K, et al. Evolution of surgical treatment for peri hilar cholangiocarcinoma : a single centre 34 year review of 574 consecutive resections. Ann Surg. 2013; 258 (1):129-40. [DOI]

6. Amir A, Rahnemai-Azar I, Jordan M, Cloyd Sharon M, Weber et al. Update on liver failure following hepatic resection: strategies for prediction and avoidance of post-operative liver insufficiency. J Clin Transl Hepatol. 2018 Mar; 6(1): 97-104. [DOI]

7. Bismuth $H$, Nakache $R$, Diamond T. Management strategies in resection for hilar cholangiocarcinoma. Ann Surg.1992;215:31-8. [DOI]

8. Aloia TA, Charnsangavej C, Faria S. High-resolution computed tomography accurately predicts resectability in hilarcholangiocarcinoma. Am J Surg. 2007; 193:702-6. [DOI]

9. Van Gulik TM, Ruys AT, Busch ORC, Rauws EAJ, Gouma DJ. Extent of liver resection for hilar

\section{CONCLUSION}

Liver parenchymal preserving bilobar wedge resection with Roux en Y intrahepatic cholangiojejunostomy could be a component of treatment in some subset of patients with hilar CCA, mainly elderly and with underlying early cirrhosis with compromised hepatic reserve. However, further research is needed to better define the inclusion criterias.

\section{ACKNOWLEDGEMENT}

Dr. Banita Gurung and Dr. Suniti Shrestha (Nepal Cancer Hospital and Research (entre) for support in frozen section biopsy.

\section{Conflict of interest: None Source(s) of support: None}

cholangiocarcinoma (Klatskin tumor): How much is enough? Dig Surg. 2011;28:141-7. [DOI]

10. Jarnagin WR, Bowne W, Klimstra DS, Ben-Porat L, Roggin K, Cymes K, et al. Papillary phenotype confers improved survival after resection of hilar cholangiocarcinoma. Ann Surg. 2005;241:703-14. [DOI]

11. Klatskin G. Adenocarcinoma of the hepatic duct at its bifurcation within the portahepatis. An unusual tumor with distinctive clinical and pathological features. Am J Med. 1965;38:241-56. [DOI]

12. Sakamoto E, Nimura Y, Hayakawa N, Kamiya J, Kondo S, Nagino $M$, et al. The pattern of infiltration at the proximal border of hilar bile duct carcinoma: a histologic analysis of 62 resected cases. Ann Surg. 1998;227:405-11. [DOI]

13. Todoroki T, Okamura T, Fukao K, Nishimura A, Otsu H, Sato $H$, et al. Gross appearance of carcinoma of the main hepatic duct and its prognosis. Surg Gynecol Obstet. 1980;150:33-40.

14. Jarnagin WR, Fong Y, DeMatteo RP, Gonen M, Burke EC, Bodniewicz BSJ, et al. Staging, resectability, and outcome in 225 patients with hilar cholangiocarcinoma. Ann Surg. 2001;234:507-17. [DOI]

15. Nagino $M$, Nimura $Y$, Nishio $H$, Ebata $T$, Igami $T$, Matsushita $M$, et al. Hepatectomy with simultaneous resection of the portal vein and hepatic artery for advanced perihilar cholangiocarcinoma: an audit of 50 consecutive cases. Ann Surg. 2010;252:115-23. [DOI]

16. Chen XP, Lau WY, Huang ZY, Zhang ZW, Chen YF, Zhang WG, et al. Extent of liver resection for hilar cholangiocarcinoma. Br J Surg. 2009;96:1167-75. [DOI] 